\title{
Splenic Pseudocyst by Aeromonas Salmonicida in Adolescent an Isolated Occurrence: A Case Report
}

Norfaidhi Akram Mat Nor, Mohd Norhisham Azmi Abdul Rahman, Ahmad Faidzal Othman

Department of Surgery, Kulliyah of Medicine, International Islamic University Malaysia.

Introduction: Aeromonas Salmonicida is a rare type of the causative agent for splenic pseudocyst. We are reporting a case of splenic pseudocyst treated with deroofing of the cyst wall. An adolescent presented to us with a history of abdominal pain, fever, and loose stool for 3 days and was investigated. Computed tomography showed huge cystic mass arising from the inferior pole of the spleen. The adolescent underwent laparotomy, drainage of splenic cyst, and deroofing of cyst wall. The culture of Aeromonas Salmonicida was growth in the cyst content. To the best of our knowledge, this is the first case of such nature. 